\title{
Scaffolding Language Development and Learning in Teacher-Student Interactions
}

\author{
Sirajo Muhammad Gulubba, Azian Abd Aziz @ Ahmad, Hema Rosheny Mustafa
}

\begin{abstract}
This paper is a review of empirical research on scaffolded teacher-student interactions in English as a Second Language (ESL) and English as a Foreign language (EFL) classrooms that covers two decades, from 2000 to 2019. Research articles were selected through different databases from Science Direct, Google Scholar, Scopus and Emerald. The review focuses on five key features of the articles, namely temporal distribution, location, research design, learning type scaffolded and level of education in which the studies were conducted. Findings of the review reveal that studies on teacher-student interactions in the ESL and EFL classrooms continue to be relevant. It was also found that scaffolding oral skills development was the most frequent pedagogic target of teacher-student interactions in the ESL and EFL classrooms. The review also revealed that the dominant research design used in these studies was the mixed mode method, with most of the studies conducted at the upper secondary and university levels. The review suggests that teacher-student scaffolded interactions in the ESL/EFL classrooms remain a potential means of helping students develop their English language communicative competence.
\end{abstract}

Index Terms: Communicative competence, Language development, Learning, Scaffolding, Teacher-student interactions

\section{INTRODUCTION}

Scaffolding is a term in the language of building construction that refers to a support structure of a building which is later removed. Bruner used the term in education, as a metaphor for supporting learners in the teaching and learning context. Scaffolding relates directly to the Zone of Proximal Development or ZPD proposed by Vygotsky in his sociocultural theory [1], [2]. The zone of proximal development is a reference to the learning potential that learners can attain by the support or assistance of a more capable person [3]. Such support is achieved through the role of the teacher as a provider of guidance and encouragement [4]. Moreover, the ZPD represents the difference between what learners are capable of and what they are not [5]. Learners' movement towards greater understanding in the process of learning occurs during shared cultural practices of the classroom context in which teacher support is absolutely indispensable [6]. [7] made a distinction between three types of scaffolding practices. The first is where scaffolding is seen as a plan of action in the way the curriculum is developed

Revised Manuscript Received on September 22, 2019.

Sirajo Muhammad Gulubba, Federal College of Education Technical Nigeria. E-mail: gulubba1 @ gmail.com

Azian Abd Aziz@Ahmad, Language Academy, Faculty of Social Sciences and Humanities, Universiti Teknologi Malaysia

Hema Rosheny Mustafa, Language Academy, Faculty of Social Sciences and Humanities, Universiti Teknologi Malaysia over a period of time. Second, scaffolding is taken to mean the procedures to be used in a given activity. Third, scaffolding is viewed as an evolving or emerging collaborative process between the expert and novice through social interaction in the classroom. [8] opines that scaffolding can be expanded to include collaboration among a group of learners who construct their learning together. For instance, a more capable learner provides assistance in the learning process of a less capable learner, thereby creating learning opportunities for both. However, the expert-novice collaborative process characterized by temporary teacher support to students' learning needs which is referred to as pedagogic scaffolding practice [8] is the main focus in this review. This is because it is this type of scaffolding that is seemingly more problematic for most practicing teachers who provide sustained rather than contingent support [9].

The pedagogic scaffolding practice has been the subject of research interests. Many teachers tend to have a misconception of what entails scaffolding, as many perceive it to be any type of support during the teaching process [6]. [9] state that this misconception has led to the rarity of good scaffolding practices among teachers in most classrooms. To clarify the concept [9] explain that for scaffolding to take place, teachers need to assess existing students' understanding before any support is given. They further state that the provision of immediate support to students without diagnoses and ascertaining students' current understanding makes scaffolding too general, which may not help the attainment of students' zone of proximal development. Teachers might, therefore, need to be trained on ways and means of appropriate scaffolding as an effective teaching strategy.

In scaffolding students' learning, the role of verbal interaction is key, emphasizing the significance of the patterns of interactions, which shape classroom discourse. Interactional patterns in which there is greater teacher control or limited students' responses in the form of predetermined short or closed answers might have little space for teacher scaffolding [10]. What is required is an interaction that is two-way or dialogic in nature, characterized by different types of teacher questions that offer greater opportunities for scaffolding to occur. Open and probing questions particularly encourage students to expand their answers, to elaborate their points and to make arguments. Patterns of interactions in which good questioning is employed do create chances for scaffolding to take place [10].

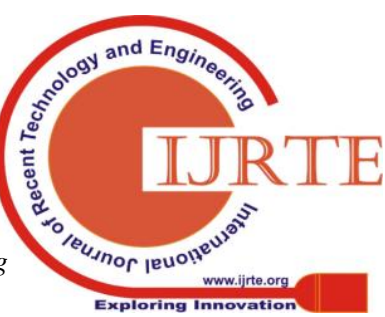


Furthermore, in these types of interactions, teachers use a higher frequency of question prompts to invite students' argumentation and interactions. In these instances, students respond not only to teacher elicitations but introduce their own discourse, which can then be extended by the teacher to allow for other students' participation and contribution. In this way, students' higher-order thinking is facilitated and problem-solving skills improved, thus making scaffolding an indispensable teaching strategy [9].

The research articles reviewed in this paper investigated scaffolding in teaching contexts where classroom talk is characterized by open dialogues between teachers and students. The focus of the empirical studies selected was on teachers' scaffolding of the development of students' English Second Language competencies.

\section{OBJECTIVES OF THE REVIEW}

The objectives of the review were to examine empirical research on scaffolding learning in the classroom contexts, focusing on developing students' ESL and EFL communicative competences. Furthermore, the review aimed at providing ESL/EFL teachers and teacher trainees an overview of studies, which had investigated scaffolding practices in actual classrooms contexts. This systematic review may also contribute to the body of knowledge in the literature on scaffolding ESL and EFL development through exploring research trends on scaffolding in various locations around the world from the year 2000 to 2019. More specifically, the objectives of this review were to identify the following:

(i) temporal distribution of the studies

(ii) location where the studies were conducted

(iii) research design used

(iv) level of education (i.e. primary, secondary, university) where the respective studies were conducted.

(v) learning type and EFL/ESL communicative competence investigated

\section{METHODOLOGY}

The focus of this review was based only on published selected research articles in educational journals between January 2000 and March 2019, which fulfilled the criteria in the key search terms used. In order to cover the trends of research on scaffolding, a two-decade range was chosen to ensure only more current studies were selected. The articles fulfilled the criteria for selection first because they have been published in reputable scholarly journals. Secondly, the contents of the studies relate to the objectives of the review. The researchers used Science direct as the main database, with additional search made via Google Scholar, Scopus and Emerald.

The different databases were browsed to retrieve articles that are related to scaffolded teacher-student interactions in English as a second language development. Following [11] as shown in Fig. 1, a systematic review and meta-analysis comprising a four-phase diagram and 27-item checklist was implemented to ensure a systematic review of the literature. Key terms were used in the search for relevant articles. These include scaffolding teacher trainees' communicative competence, scaffolding pre-service teachers' ESL proficiency, scaffolding ESL learning, scaffolding development of students' ESL competence. Using these key terms yielded a total of 1,129 research articles. Duplicates were then eliminated, leaving 513 articles. The number of articles was further reduced based on the year of publication and the articles' availability via open access. This finally brought the number of eligible articles for analysis to 23 , comprising 6 qualitative studies, 6 quantitative studies and 11 mixed mode studies as displayed in Figure 1.

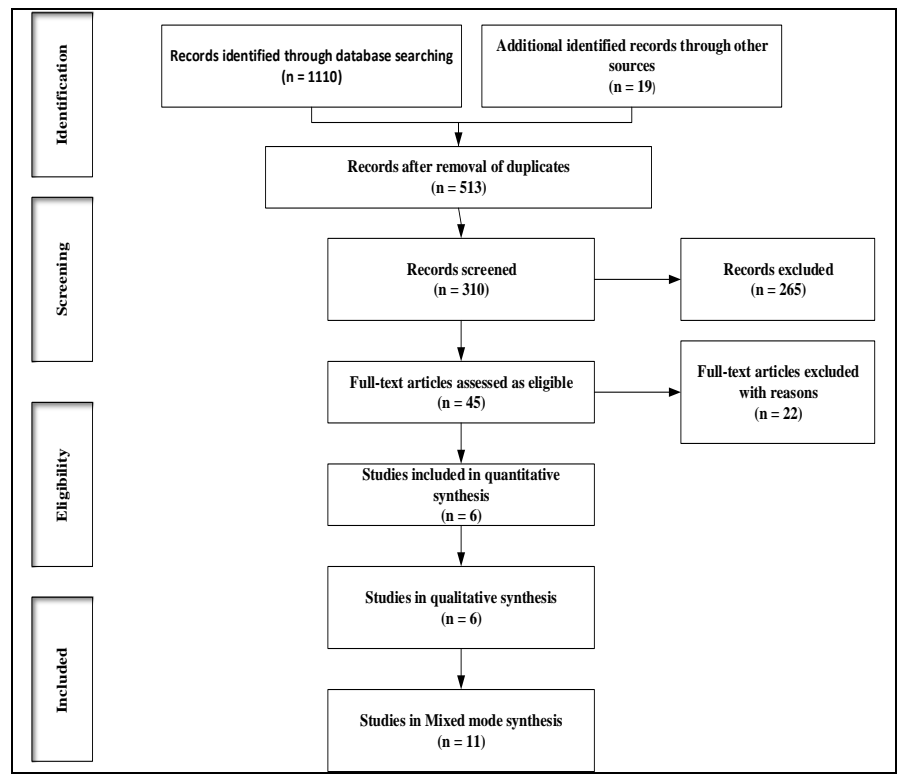

Fig. 1. Flow diagram of Systematic Review of journal articles selected for the study

\section{FINDINGS AND DISCUSSION}

Table 1 shows an overview of the twenty-three (23) selected articles. The subsequent sub-sections describe and discuss findings of this study based on each research objective.

Table 1. Overview of Journal Articles on Teacher-Student Scaffolding Selected for Study

\begin{tabular}{|c|c|c|c|}
\hline No. & Author/Year & Location & $\begin{array}{l}\text { Research } \\
\text { Design }\end{array}$ \\
\hline 1 & $\begin{array}{l}\text { Tawfik et al, } \\
\text { (2018) }\end{array}$ & USA & $\begin{array}{l}\text { Quantitativ } \\
\mathrm{e}\end{array}$ \\
\hline 2 & $\begin{array}{l}\text { Khaliliaqdam } \\
\text { (2014) }\end{array}$ & Iran & Qualitative \\
\hline 3 & $\begin{array}{l}\text { Mahroof (2017) } \\
{[15]}\end{array}$ & Sri Lanka & $\begin{array}{l}\text { Mixed } \\
\text { Mode }\end{array}$ \\
\hline 4 & $\begin{array}{l}\text { Birjandi \& Jazebi } \\
\text { (2014) }\end{array}$ & Iran & $\begin{array}{l}\text { Mixed } \\
\text { Method }\end{array}$ \\
\hline 5 & $\begin{array}{l}\text { Lefstein et al., } \\
(2018)\end{array}$ & Israel & $\begin{array}{l}\text { Mixed } \\
\text { Mode }\end{array}$ \\
\hline 6 & $\begin{array}{l}\text { Van de Pol et al } \\
\text { (2012) }\end{array}$ & Netherlands & $\begin{array}{l}\text { Mixed } \\
\text { Mode }\end{array}$ \\
\hline 7 & $\begin{array}{l}\text { McNeil (2012) } \\
{[18]}\end{array}$ & South Korea & Mixed \\
\hline
\end{tabular}




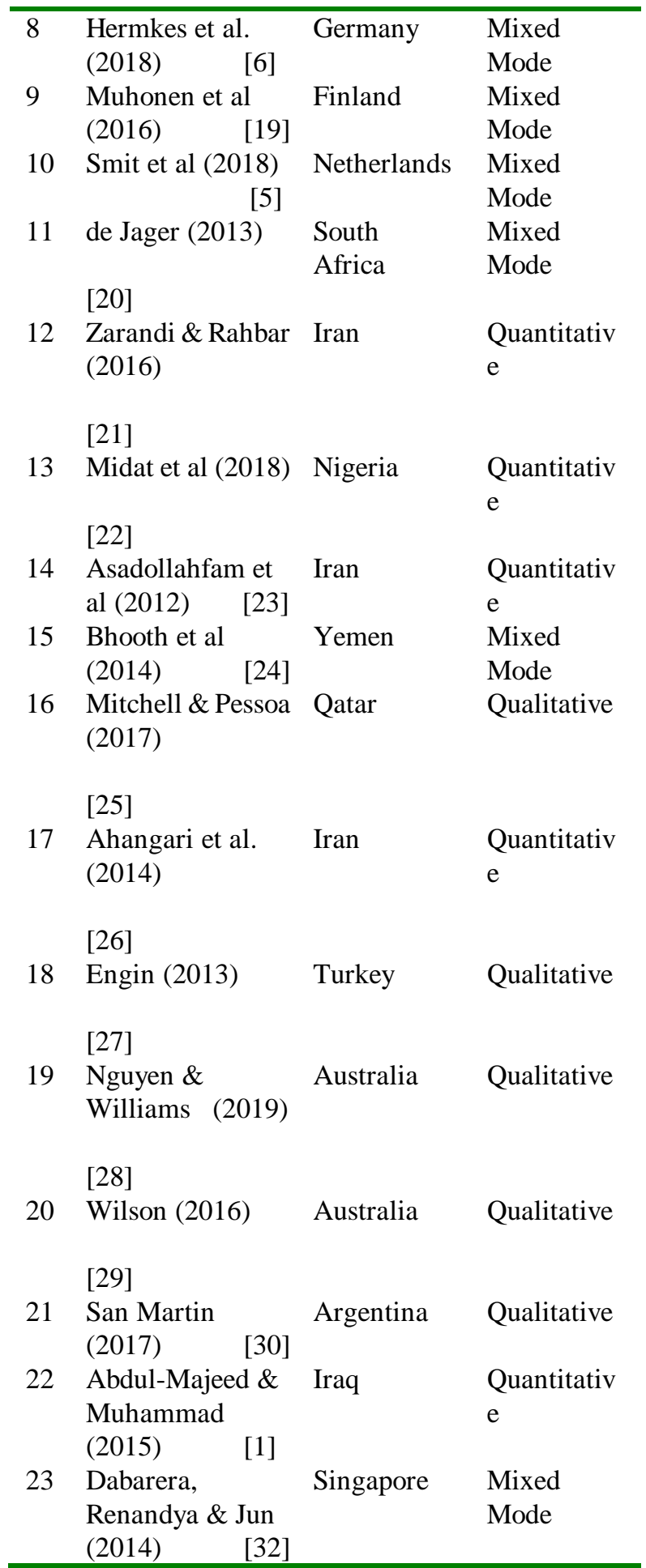

\section{A. Temporal Distribution of Reviewed Studies}

Table 2 provides an analysis of the 26 articles that have been selected covering two decades (2000-2019) of research on scaffolding students' learning. The distribution shows a dispersal of the published articles over the 20-year period with a fluctuating increase and decrease of the trend in publications in the research area.
Table 2. Temporal Distribution of Studies

\begin{tabular}{ccc}
\hline $\begin{array}{c}\text { Publication } \\
\text { Year of Selected } \\
\text { Article }\end{array}$ & Frequency & $\begin{array}{c}\text { Percentage } \\
(\%)\end{array}$ \\
\hline 2010 & 0 & 0 \\
2011 & 0 & 0 \\
2012 & 3 & 13.0 \\
2013 & 2 & 8.6 \\
2014 & 5 & 21.7 \\
2015 & 1 & 4.3 \\
2016 & 3 & 13.0 \\
2017 & 3 & 13.0 \\
2018 & 5 & 21.7 \\
2019 & 1 & 4.3 \\
Total & & \\
\hline
\end{tabular}

From Table 2, it is apparent that no articles from 2000 to 2011 qualified to be reviewed for the purpose of this study. However, from 2012 to 2013 five articles fulfilled the criteria for selection. From 2014 to 2017, twelve articles were published with the highest number of five articles recorded in both 2014, representing $21.7 \%$. There was a decline in 2015 with the publication of only one article and a slight increase in 2016 with 3 published articles. Findings of the literature review reveal that students on teacher-student interactions suffered a decline from 2000 to 2011, but enjoyed a revival of interest among researchers commencing 2012 up to the present day. This suggests that studies related to teacher-student interactions and scaffolding continue to be seen by researchers as offering a positive contribution towards the teaching and learning of English as a second language.

\section{B. Location of Reviewed Studies}

Table 3. Location of Studies

\begin{tabular}{lcc}
\hline \multicolumn{1}{c}{ Location } & $\begin{array}{c}\text { No. of } \\
\text { Studies }\end{array}$ & $\begin{array}{c}\text { Percentage } \\
(\%)\end{array}$ \\
\hline North America (U.S.A.) & 1 & 4.3 \\
South America & 1 & 4.3 \\
Europe & 4 & 17.3 \\
Asia & 4 & 17.3 \\
Middle East & 9 & 39.1 \\
Australia & 2 & 8.6 \\
Africa & 2 & 8.6 \\
& & \\
Total & 23 & 100 \\
\hline
\end{tabular}

Evidence in Table 3 shows that in general, most studies on teacher-student interactions and scaffolding in the ESL classroom were conducted in countries where the native language is not English. The data shows that the region with the highest number of this type of research was the Middle East, which represents $39.1 \%$ of the reviewed studies. 
This was followed by Europe and Asia both with $17.3 \%$. In contrast, not many such studies were conducted in English speaking regions and countries like North America (U.S.A.) and Australia, with each country respectively forming $4.3 \%$ of the reviewed studies.

This gives credence to Kachru's Three Circles Model of native English speaker inner circle and non-native outer and expanding circle of English as a global, second or foreign language [33]. It also reinforces Kachru's [34] arguments on the importance of research of English teaching and learning in ESL and EFL contexts as depicted by the results in this review.

\section{Research Design Employed in Reviewed Studies}

The reviewed studies employed one of three popular research designs as shown in Table 4 below.

Table 4. Research Design Employed

\begin{tabular}{lcc}
\hline Research Design & Frequency & $\begin{array}{c}\text { Percentage } \\
(\%)\end{array}$ \\
\hline Qualitative & 6 & 26.0 \\
Quantitative & 6 & 26.0 \\
Mixed Mode & 11 & 47.8 \\
& & \\
Total & 23 & 100 \\
\hline
\end{tabular}

As can be seen from Table 4, of the three research designs, the dominant design employed was the mixed mode method. Nearly $50 \%$ of the studies reviewed opted for this research design. This is probably because the combination of qualitative and quantitative research design provides better understanding of the problem being investigated in comparison to using only one or the other method [35].

\section{Education Level Involved in Reviewed Studies}

Table 5. Education Level where Studies were Conducted

\begin{tabular}{ccc}
\hline Level of Education & Frequency & $\begin{array}{c}\text { Percentage } \\
(\%)\end{array}$ \\
\hline Primary School & 3 & 13.0 \\
Low/Junior Secondary & 2 & 8.6 \\
High/Upper Secondary & 9 & 39.1 \\
College/University & 9 & 39.1 \\
Total & 23 & 100 \\
\hline
\end{tabular}

Table 5 shows where - in terms of level of education - the selected studies were conducted. Secondary school teachers and students formed the highest group of participants investigated, making up $47.7 \%$ of the studies of the reviewed articles with $42.3 \%$. This was closely followed by studies conducted at the university level, with $39.1 \%$. This suggests that researchers might perceive teacher-student interactions and scaffolding to have a greater impact on students who are more matured.

\section{E. Learning Scaffolded}

Table 5. Learning Scaffolded in Reviewed Studies

\begin{tabular}{lcc}
\hline \multicolumn{1}{c}{ Learning Scaffolded } & Frequency & $\begin{array}{c}\text { Percentage } \\
(\%)\end{array}$ \\
\hline $\begin{array}{l}\text { Developing EFL/ESL Oral } \\
\text { Skills }\end{array}$ & 7 & 30.4 \\
Developing ESL/EFL & 1 & 4.3 \\
Grammar & 4 & 17.3 \\
$\begin{array}{l}\text { Developing ESL/EFL Reading } \\
\text { Developing EFL/ESL Writing }\end{array}$ & 2 & 8.6 \\
$\begin{array}{l}\text { Developing English as an } \\
\text { Additional Language (EAL) }\end{array}$ & 1 & 4.3 \\
Instruction & & \\
$\begin{array}{l}\text { Developing Teacher } \\
\text { Professional Practice } \\
\text { Coding Scaffolding }\end{array}$ & 6 & 26.0 \\
Total & 2 & 8.6 \\
\hline
\end{tabular}

Table 5 shows that most of the reviewed studies investigated the development of communicative competence in English as a second or foreign language context. Oral skills development had the highest count of 7 with $30.0 \%$. This emphasizes the significance of oral skill and the need to help students overcome its challenges in ESL learning contexts [36]. This was followed by studies that investigated 'reading' with $17.3 \%$, with 'writing' and 'grammar' receiving the least attention with $8.6 \%$ and $4.3 \%$ respectively. The disinterest in grammar seems somewhat perplexing as grammar in fact requires additional attention since it is the resource for developing other competencies [37]. As a whole, the development of students' ESL/EFL competencies in oral reading and writing skills as well as grammar comprised $60.6 \%$ of the articles put together. However, 7 of the articles in fact focused on trainee teachers and how scaffolding may assist their instructional language. These studies comprised 1 (4.3\%) scaffolding for English as an Additional Language (EAL) instruction, and 6 (26.0\%) that focused on developing teacher professional practice. This indicates that investigations on scaffolding should not only focus on developing ESL/EFL students' language competencies, but should also include investigations involving teacher trainees or would be teachers.

\section{CONCLUSION}

Based on the tabular presentations, analysis and interpretation of results in this review, it is apparent that there is renewed interest in research on scaffolding, which in different ways benefit students' learning. Many of the studies concentrated on developing the communicative competence of non-native ESL/EFL students. The temporal distribution of the reviewed research tend to favour the Middle East and Europe, with not many investigating scaffolding in other non-native speaking contexts such as Asia and Africa. 
The results also showed interest in investigating scaffolding in areas such as EAL and teacher development. Findings of this paper suggest that there is a revival of interest on studies investigating scaffolding, be it in the teacher-student or teacher trainer-teacher trainee contexts. Research in the interactional methodology of teacher scaffolding could indeed provide significant insights into helping teachers improve their pedagogic scaffolding practice. The insights could provide the focus for the professional development of teachers. This can, in turn, have a greater impact on students' learning, thereby improving their ESL/EFL communicative skills.

\section{REFERENCES}

1. M.R. Abdul-Majeed and N.M. Muhammad. The effect of using scaffolding strategies on EFL students' reading comprehension achievement. Al-Adab Journal. vol. 111, 2015, pp. 91-118.

2. A. Lefstein, D. Vedder-Weiss, I. Tabak and A. Segal. Learner agency in scaffolding: The case of coaching teacher leadership. International Journal of Educational Research. vol. 90, Jan 2018, pp. 209-22.

3. C.C. Goh. Research into practice: Scaffolding learning processes to improve speaking performance. Language Teaching. vol. 50, Apr 2017, pp. 247-60.

4. E. Arshavskaya. Analyzing mediation in dialogic exchanges in a pre-service second language (L2) teacher practicum blog: A sociocultural perspective. System. Vol. 45, Aug 2014, pp.129-37.

5. J. Smit, M. Gijsel, A. Hotze, and A. Bakker. Scaffolding primary teachers in designing and enacting language-oriented science lessons: Is handing over to independence a fata morgana?. Learning, Culture and Social Interaction. vol. 18, Sep 2018 Sep, pp.72-85.

6. R. Hermkes, H. Mach and G. Minnameier. Interaction-based coding of scaffolding processes. Learning and Instruction. vol. 54, Apr 2018, pp. $147-55$. conceptual framework. International Journal of Bilingual Education and Bilingualism. vol. 9, Mar 2006, pp.159-80.

8. L. Van Lier. Interaction in the language curriculum: Awareness, autonomy and authenticity. Routledge, 2014.

9. J. van de Pol, M. Volman and J. Beishuizen. Promoting teacher scaffolding in small-group work: A contingency perspective. Teaching and Teacher Education. vol. 28, Feb 2012, pp.193-205.

10. R.M. Gillies. Dialogic interactions in the cooperative classroom. International Journal of Educational Research. vol. 76. Jan 2016, pp. $178-89$.

11. L. Shamseer, D. Moher, M. Clarke, D. Ghersi, A. Liberati, M. Petticrew, P. Shekelle and L.A. Stewart. Preferred reporting items for systematic review and meta-analysis protocols (PRISMA-P) 2015: elaboration and explanation. Bmj. 349, g7647, Jan 2015.

12. O. Gerakopoulou. Scaffolding oral interaction in a CLIL context. Unpublished thesis. Spain: University of Madrid. 2011.

13. A.A. Tawfik, V. Law, X. Ge, W. Xing and K. Kim K. The effect of sustained vs. faded scaffolding on students' argumentation in ill-structured problem solving. Computers in Human Behavior. Vol. 87, Oct 2018, pp. 436-49.

14. S. Khaliliaqdam. ZPD, scaffolding and basic speech development in EFL context. Procedia-Social and Behavioral Sciences. Vol. 98, May 2014, pp. 891-7.

15. S.R. Mahroof. Scaffolding interaction in English as a second language classroom: a socio-cultural analysis. 2017. Proceedings of $7^{\text {th }}$ International Symposium, SEUSL, 7th \& 8th December 2017

16. A. Dahlberg. Translanguaging as a scaffolding structure in a multilingual http://www.diva-portal.org/smash/get/diva2:1083686/FULLTEXT01.pdf

17. P. Birjandi and S. Jazebi. A comparative analysis of teachers' scaffolding practices. International Journal of Language and Linguistics, vol. 2, 2014, pp.154-64.

18. L. McNeil. Using talk to scaffold referential questions for English language learners. Teaching and Teacher Education, vol 28, Apr 2012, pp.396-404.

19. H. Muhonen, H. Rasku-Puttonen, E. Pakarinen, A.M. Poikkeus, M.K Lerkkanen. Scaffolding through dialogic teaching in early school classrooms. Teaching and Teacher Education. vol. 55, Apr 2016, pp. 143-54.

20. T. de Jager. Scaffold lecturing methods to improve english second language science student teachers'academic performance. International Journal of Arts \& Sciences. vol 6, Jan 2013, pp. 67.
7. A. Walqui. Scaffolding instruction for English language learners: A group studying English in Sweden. Retrieved from

21. S.Z. Zarandi and B. Rahbar. Enhancing speaking ability through intervening scaffolding strategies. Theory and Practice in Language Studies. vol 6, Nov 2016, pp. 2191-5.

22. C. Midat, C. Malchy, S. Finfang, N. Dashe, and M. Awwal. Effects Of Multimedia And Scaffolding Strategies On The Perfomance Of Senior Secondary Schools Students In English Language Speaking Skills, Kaduna State, Nigeria. International Journal of Advanced Research and Publications, vol 2, 2018, pp. 16-18.

23. H. Asadollahfam, D. Kuhi, A. Salimi and S. Mirzaei, S. The Effect of Incidental Focus on Form and Scaffolding on SL Learners' Accuracy Procedia - Social and Behavioral Sciences, vol 46, 2012, pp. 663-671.

24. A. Bhooth, H. Azman and K. Ismail. The role of the L1 as a scaffolding tool in the EFL reading classroom. Procedia-Social and Behavioral Sciences, vol 118, Mar 2014, pp. 76-84.

25. T.D. Mitchell and S. Pessoa. Scaffolding the writing development of the Argument genre in history: The case of two novice writers. Journal of English for Academic Purposes, vol 30, Nov, pp. 26-37.

26. S. Ahangari, M. Hejazi and L. Razmjou. The impact of scaffolding on content retention of Iranian post-elementary EFL learners' summary writing. Procedia-Social and Behavioral Sciences, vol 98, May 2014, pp 83-9.

27. M. Engin. Questioning to scaffold: an exploration of questions in pre-service teacher training feedback sessions. European Journal of Teacher Education, vol. 36, Feb 2013, pp. 39-54.

28. M.H. Nguyen, C. Penry Williams. A preservice teacher's learning of instructional scaffolding in the EAL practicum. Australian Journal of Language and Literacy. (In press), 2019.

29. K. Wilson. Critical reading, critical thinking: Delicate scaffolding in English for Academic Purposes (EAP). Thinking Skills and Creativity, vol 22, Dec 2016, pp. 256-65.

30. M.G. San Martín. Scaffolding the Learning-to-Teach Process: A Study in an EFL Teacher Education Programme in Argentina. Profile Issues in TeachersProfessional Development. vol 21, Jun 2018, pp.121-34.

31. L.D. McKenzie. Scaffolding English language learners' reading performance. Walden Dissertations and Doctoral Studies Collection at ScholarWorks. 2011

32. C. Dabarera, W.A. Renandya and L.J. Zhang. The impact of metacognitive scaffolding and monitoring on reading comprehension. System. Vol 42, Feb 2014., pp 462-73.

33. S. Karami and M. Zamanian. A Review of English Teaching Practices in the Philippines. Journal of Language Sciences \& Linguistics. vol. 4, 2016, pp. 23-9.

34. B.B.Kachru. The other tongue: English across cultures. University of Illinois Press, 1992.

35. J. Creswell. Education research: Planning, conducting and evaluating quantitative and qualitative research. Boston, MA: Person Education.

36. M. Bygate. Speaking. Oxford University Press, Jun1987.

37. M. Canale and M. Swain. Theoretical bases of com-municative approaches to second language teaching and testing. Applied linguistics. vol. 1, 1980, pp. $1-47$

\section{AUTHORS PROFILE}

Sirajo Muhammad Gulubba is a lecturer with Federal College of Education Technical Gusau Zamfara, Nigeria. He studied BA Ed English at Usmanu Danfodio University Sokoto. I did MA Teaching English to speakers of other languages (TESOL) at the University of Leeds, UK. As senior lecturer, I headed the Department of English and later served as the Dean, School of Languages Education. I won the British Council 2007 English teachers Hornby Scholarship for Nigeria which funded my MA programme. I was a member of the team of trainers for the TKT and CLIL workshops for secondary school teachers across Nigeria.

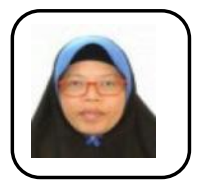

Azian Abd Aziz @ Ahmad is a senior lecturer at Universit Teknologi Malaysia, She holds a Ph.D., M.Ed. and Diploma in Teaching English as a Second language (TESL) and a B.Sc. in Estate Management. Her teaching career spans over 30 years, mostly at the tertiary level. Her research interests centre on classroom discourse and ESL teaching and learning processes. Her work has been published in Scopus indexed journals such as Systems and $3 \mathrm{~L}$ : Language, Linguistics and Literature. 
Dr Hema Rosheny Mustafa obtained her PhD in 2017 from the University of Tasmania, Australia. Her research investigated the use of Facebook among parents of a child with Autism. Her other research interest includes ESL, teacher education, and communication. Currently she is working on the new MUET-CEFR materials which will be launched in September. She has recently been accepted as Co-PI for a research project with Universitas Airlangga, Surabaya, Indonesia, under 2019 SATU Joint Research Scheme. She has more than 15 years of teaching English in secondary and tertiary education. She is currently heading the MyLinE unit which manages online learning in English portal that is subscribed by users in various countries including Malaysia, Bangladesh and China. 